\title{
Kısıntılı Sulama Koşullarında Bazı Pamuk (Gossypium hirsutum L.) Genotiplerinin Kuraklık Toleransının Belirlenmesi

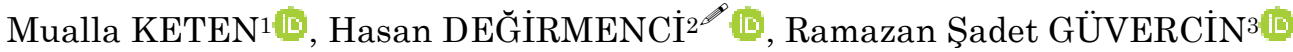 \\ 1,2Kahramanmaraş Sütçü İmam Üniversitesi, Ziraat Fakültesi, Biyosistem Mühendisliği Bölümü, Kahramanmaraş, ${ }^{3}$ Kahramanmaraş Sütçü \\ İmam Üniversitesi, Türkoğlu Meslek Yüksekokulu, Bitkisel ve Hayvansal Üretim Bölümü, Kahramanmaraş \\ ${ }^{1}$ https://orcid.org/0000-0001-7741-922X, ${ }^{2}$ https://orcid.org/0000-0002-6157-816X, ${ }^{3}$ https://orcid.org/0000-0002-6195-5762 \\ $\varangle:$ degirmenci@ksu.edu.tr
}

\section{ÖZET}

$\mathrm{Bu}$ çalışmanın amacı, sulama suyunda belirli oranlarda kısıntı yaparak suyu daha verimli kullanmak ve kuraklığa toleransı yüksek pamuk genotiplerini belirlemektir. Çalışmada 7 farklı genotip (Aday 1, Aday 2, Aday 3, Aday 4, Aday 5, Aday 6 ve Aday 7) ve Stonville 468 pamuk çeşidi kullanılmıştır. Kuraklık toleransını belirlemek için Stres Duyarlılık İndeksi (SSI), Verim Kararlılık İndeksi (YSI), Verim Azalma Oranı (Yr), Verim İndeksi (YI), Toleranslılık İndeksi (TOL), Ortalama Verimlilik (MP), Harmonik Ortalama (HM), Geometrik Ortalama Verimliliği (GMP), Modifiye Edilmiş Stres Toleranslılık İndeksleri ( $\mathrm{K}_{1} \mathrm{STI}$-potansiyel verim değerlerinden elde edilerek hesaplanan indeks, $\mathrm{K}_{2} \mathrm{STI}^{-}$stres koşullarında elde edilen verim değerleriyle hesaplanan indeks) ve Stres Toleranslılık İndeksi (STI) kullanılmıştır. HM, MP, GMP, STI, K $\mathrm{K}_{1}$ STI indekslerinin stresli ve stressiz koşullarda uygulanabilirliği Aday 4 genotipinde görülmüştür. En yüksek MP değeri, Aday 6 genotipinde bulunmuştur.. En düşük SSI indeksi Aday 2'de bulunmuş ve kuraklığa toleranslı olduğunu göstermiştir. Ortalama karşılaş̧ırma (LSD), temel bileşenler analizi (PCA) ve kümeleme (Cluster) analizi sonucunda Aday 2 genotipinin kuraklığa yüksek oranda toleranslı olduğu görülmüştür.

\section{Araştırma Makalesi}

Makale Tarihçesi

Geliş : 07.01.2019

Kabul : 18.04.2019

\section{Anahtar Kelimeler}

Kuraklığa duyarlılık indeksi,

Kisintılı sulama,

Pamuk,

Kümeleme analizi

Determination of Drought Tolerance for Some Cotton Genotypes (Gossypium hirsutum L.) under Deficit Irrigation Conditions

\section{ABSTRACT}

The aim of this study was to use water more efficiently and determine drought-tolerant cotton genotypes by reducing the irrigation water at certain rates. In this study, 7 different cotton genotypes (Aday 1, Aday 2, Aday 3, Aday 4, Aday 5, Aday 6, and Aday 7) and a control variety (Stonville 468) were used. In order to determine drought tolerance, parameters including Stress Susceptibility Index (SSI), Yield Stability Index (YSI), Yield Reduction Ratio (Yr), Yield Index (YI), Tolerance Index (TOL), Mean Productivity (MP), Harmonic Mean (HM), Geometric Mean Productivity, Modified Stress Tolerance (K1STIindex calculated from potential yields, K2STI- index calculated from yield values in stress conditions) Stress Tolerance Index (STI) and Yield Strength Index (YSI) were used. Stressed and non-stress conditions applicability of HM, MP, GMP, STE, K1STI indices has appeared in Aday 4 genotypes. The highest value of MP was found in Aday 6 genotype. The lowest SSI index was in genotype Aday 2. As a result of the mean comparison (LSD), principal component analysis (PCA) and cluster analysis, the Aday 2 genotype was found highly tolerant to drought under non stress conditions.

\section{Research Article}

Article History
Received: 07.01 .2019
Accepted: 18.04 .2019

Keywords

Drought sensitive index

Deficit irrigation

Cotton

Cluster analyses

To Cited: Keten M, Değirmenci H, Güvercin RŞ 2019. Kısıntılı Sulama Koşullarında Bazı Pamuk (Gossypium hirsutum L.) Genotiplerinin Kuraklık Toleransının Belirlenmesi. KSÜ Tarim ve Doğa Derg 22(5): 685-693, DOI: 10.18016/ksutarimdoga.vi.509483. 


\section{GİİS}

Pamuk bitkisi lifi, yağı ve küspesi ile bir çok alanda kullanılan endüstriyel bir tarla bitkisidir. Kahramanmaraş ili yarı kurak iklime sahip olduğundan yağışlar pamuk yetiştiriciliği için yetersizdir. Sulama diğer bitkilerde olduğu gibi pamuk yetiştiriciliğinde de son derece önemlidir. Su kaynaklarının yetersiz oluşu, her alanda olduğu gibi tarım alanında da suyu daha verimli kullanmayı gerektirir. Suyu daha verimli kullanmak için su kaynaklarının doğru değerlendirilmesi, mevcut suyun korunması ve fazla su harcamasının önüne geçilmesi gerekmektedir. Su kaynaklarını israf etmeden tarımda üretim yapabilmek için kısıntılı sulama yapmanın yanında kuraklığa toleranslı çeşitler kullanılmalıdır. Daha önceki yapılan bazı çalışmalarda sulama suyunda yapılan belli miktardaki kısıntıların bitkilerin yeterli sulandığı koşullarla kıyaslandığında ciddi verim düşüklüğü olmadığını Kaçar ve Ünlü (2008) ile Maya (2007) yaptıkları çalışmalarda göstermişlerdir.

Gelecekte yaşanması muhtemel bir kuraklık ve su kıtlığına karşı hazırlıklı olunması için kuraklığa dayanıklı çeşitlerin de geliştirilmesi gerekmektedir. Kuraklığa dayanıklı çeşitlerin tespit edilmesi için birçok indeks geliştirilmiştir. Bu indeksler bitkilerin su stresi ve su stresinin olmadığ 1 koşullardaki verimlerinden yola çıkılarak oluşturulmuştur. Tolerans indeksleri kurak koşullar altındaki verim kaybına bağlı olarak kuraklığa dayanıklı genotipleri seçmek için kullanılır (Mitra, 2001; Anwar ve ark., 2011). Bu indeksler sayesinde bir genotipin kuraklığa toleransı belirlenebildiği gibi kuraklığa duyarlılığı da belirlenmiş olur. Bir genotipin kuraklılığa duyarlılığ su stresi altında verimdeki azalmanın bir fonksiyonu olarak görülür (Blum, 1988). Genotiplerin kuraklığa dayanımlarının değerlendirilebilmesi için geliştirilen indeksler stresli ve stressiz koşullar arasındaki matematiksel ilişkiye bağlı olarak belirlenir (Sabaghina ve Janmohammadi, 2014).

Fischer ve Maurer (1978) kuraklık ortamındaki tohum verimlerinin kuraklığa dirençli indeks olarak düşünülebileceğini belirtmiştir. Khalili ve ark. (2012) STI ve GMP indekslerinin strese dayanıklı ve yüksek verimli genotiplerin seçimi için daha doğru kriterler olduğunu göstermiştir. Ganjali ve ark. (2009) MP, GMP, STI ve HM ile stresli ve stressiz koşulların verimleri arasında pozitif ve yüksek derecede anlamlı korelasyonlar bulmuştur. Jabbari ve ark. (2008), STI ile stresli ve stressiz koşullar altındaki verimler arasında pozitif ve önemli korelasyonlar bulmuştur. Drikvand ve ark. (2012) sulanan ve sulama yapılmayan (susuz) koşullar altında genotiplerin tanımlanması için en uygun indeksin GMP, MP, STI olduğunu bildirmiştir. Anwar ve ark. (2011) stresli ve stressiz koşullar altında tane verimi ile MP, HM,
GMP, STI ve $\mathrm{K}_{1}$ STI arasında pozitif ve önemli bir ilişki gözlemlemiştir.

Türkiye'de ekonomik değeri yüksek olan pamuk bitkisinden daha iyi sonuç alabilmek için sulama ölçütlerinin ortaya konulması gerekmektedir. Kahramanmaraş ilinde üretim bakımından pamuk verimi ve lif kalitesi düşüktür. Özellikle verim artışı ve girdilerin azaltılması yönünde yapılacak çalışmalar üretici gelirlerinin artmasına, tekstil, yağ ve yem sektörünün de gelişmesine katkı sağlayacaktır. Bu amaçla çalışmada pamukta verim ve kaliteyi azaltmadan farklı sulama suyu seviyelerinin uygulanabilirliği araştırılmış, yarı stresli koşullarda yetiştirilen pamuk bitkilerinin kuraklığa toleransı gösterilmiş ve tolerans indeksleri arasıdaki karşılıklı ilişki incelenmiştir.

\section{MATERYAL ve YÖNTEM}

Materyal

\section{Deneme alanina ait iklim ve toprak özellikleri}

Kahramanmaraş Doğu Akdeniz Geçit Kuşağı Tarımsal Araştırma Enstitüsünde (DAGTEM) 2015 yılında yürütülen çalışma alanının rakımı $465 \mathrm{~m}$ olup $37^{\circ} 55^{\prime} 08^{\prime \prime}$ kuzey paraleli ve $36^{\circ} 55^{\prime} 09^{\prime \prime}$ doğu meridyeni arasındadır. Araştırmanın yürütüldüğü bölgede tipik Akdeniz ikliminin özellikleri görülmektedir. Meteorolojik verilere göre çalışma alanının ortalama yıllık sıcaklığı $16.85{ }^{\circ} \mathrm{C}$ iken yıllık ortalama yağışı 710 mm olmaktadır (Anonim, 2015). Yazları çoğunlukla kurak geçerken yağışların büyük bir kısmı kışın görülür. Pamuk yetiştirme dönemi için çalışılan alanda belirlenen uzun yıllık ve yıllık ortalama iklim verileri Çizelge 1'de verilmiştir (Anonim, 2015).

Yetişme sezonu boyunca en yağışlı geçen ayın Mayıs olduğu gözlenirken en sicak geçen ay Temmuz olmuştur. En yüksek oransal nem Haziran ayında gözlenirken, en düşük oransal nem bitkinin hasat dönemine denk gelen Eylül ayında görülmüştür. Ekim ayında en düşük rüzgar hızı görülürken, Temmuz ayında rüzgar hızı en yüksek değere çıkmıştır. Pamuk bitkisi yaklaşık altı ayda hasat olgunluğuna gelmiştir. Hava sıcaklıkları uzun yıllar ortalamasıyla karşılaştırıldığı zaman pamuğun vejetasyon süresi boyunca minimum sicaklıkların yükseldiği, maksimum sıcaklıkların ise düştüğü görülmektedir.

Deneme alanına ait toprağın bazı fiziksel ve kimyasal özellikleri Çizelge 2'de verilmiştir.

Çizelge 2'de görüldüğü gibi $90 \mathrm{~cm}$ profil derinliğindeki kullanılabilir su miktarının $126.0 \quad \mathrm{~mm}$ olduğu belirlenmiştir. Çizelge 2'ye göre toprağın hafif alkali, tuzsuz olduğu ve hacim ağırlığının 1.46-1.43 $\mathrm{gcm}^{-3}$ arasında değiştiği görülmektedir. Çalışma alanına ait toprağın bünyesi $0-30 \mathrm{~cm}$ ve $30-60 \mathrm{~cm}$ katmanları arasında killi-tınlı iken 60-90 cm katmanında kumlukilli tın olduğu görülmüştür. 
Çizelge 1. 2015 yılı Kahramanmaraş ili yıllık ve uzun yıllık ortalama iklim verileri

\begin{tabular}{|c|c|c|c|c|c|c|c|}
\hline Yillar & İklim parametreleri & Mayıs & Haziran & Temmuz & Ağustos & Eylül & Ekim \\
\hline \multirow{6}{*}{2015} & Maks.sıcaklık (ㄷ) & 35.40 & 35.50 & 43.10 & 41.90 & 40.60 & 25.60 \\
\hline & Min. sıcaklık (C) & 10.90 & 15.30 & 18.30 & 15.20 & 15.10 & 3.50 \\
\hline & Ort. sicaklık $\left({ }^{\circ} \mathrm{C}\right)$ & 20.80 & 24.40 & 29.02 & 28.84 & 27.44 & 14.05 \\
\hline & Toplam yağı̧̧ (mm) & 63.80 & 1.00 & 1.00 & 7.20 & 0.20 & 0.00 \\
\hline & Oransal nem (\%) & 48.00 & 48.30 & 42.37 & 44.98 & 37.50 & 39.35 \\
\hline & Rüzgar hızı $\left(\mathrm{m} \mathrm{s}^{-1}\right)$ & 1.30 & 2.40 & 9.87 & 8.20 & 3.60 & 1.14 \\
\hline \multirow{6}{*}{$1950-2014$} & Maks.sıcaklık $\left({ }^{\circ} \mathrm{C}\right)$ & 38.00 & 42.00 & 45.20 & 44.40 & 41.30 & 37.20 \\
\hline & Min. sıcaklık ( $\left.{ }^{\circ} \mathrm{C}\right)$ & 5.00 & 10.30 & 15.60 & 15.70 & 8.60 & 0.00 \\
\hline & Ort. sıcaklık (C) & 20.30 & 25.20 & 28.30 & 28.40 & 25.10 & 19.00 \\
\hline & Toplam yağı̧̧ (mm) & 38.90 & 7.20 & 1.20 & 0.80 & 8.50 & 44.70 \\
\hline & Oransal nem (\%) & 54.60 & 50.60 & 52.40 & 54.30 & 51.60 & 55.10 \\
\hline & Rüzgar hızı $\left(\mathrm{m} \mathrm{s}^{-1}\right)$ & 1.90 & 2.90 & 3.20 & 2.90 & 2.10 & 1.00 \\
\hline
\end{tabular}

Çizelge 2. Deneme alanına ait toprakların fiziksel ve kimyasal özellikleri

\begin{tabular}{lllllllllllllll}
\hline $\begin{array}{l}\text { Toprak } \\
\text { derinliği } \\
(\mathrm{cm})\end{array}$ & $\begin{array}{l}\mathrm{TK} \\
(\%)\end{array}$ & $\begin{array}{l}\mathrm{SN} \\
(\%)\end{array}$ & $\begin{array}{l}\mathrm{Yt} \\
\left(\mathrm{gcm}^{-3}\right)\end{array}$ & $\mathrm{pH}$ & \multicolumn{3}{l}{$\begin{array}{l}\mathrm{EC} \\
\left(\mathrm{dScm}^{-1}\right)\end{array}$} & $\begin{array}{l}\text { Katyonlar } \\
\left(\mathrm{mel}^{-1}\right) \\
\mathrm{Na}^{+}\end{array} \mathrm{K}^{+}$ & \multicolumn{4}{c}{ Anyonlar(mel-1) } \\
\hline $0-30$ & 26.34 & 13.22 & 1.46 & 8.26 & 0.175 & 0.08 & 0.07 & 5.34 & 3.18 & 4.66 & 3.38 & 0.26 & $\mathrm{CL}$ \\
$30-60$ & 23.05 & 15.52 & 1.46 & 8.40 & 0.212 & 0.1 & 0.08 & 5.18 & 2.96 & 4.67 & 3.23 & 0.99 & $\mathrm{CL}$ \\
$60-90$ & 23.07 & 14.81 & 1.43 & 8.52 & 0.256 & 0.11 & 0.06 & 4.93 & 3.34 & 4.04 & 3.42 & 0.78 & SCL \\
\hline
\end{tabular}

TK: Tarla kapasitesi, SN: Solma noktası, Yt: Hacim ağırlı̆̆ı, EC: Elektriksel iletkenlik, CL: Killi tın, SCL: Kumlu killi tın

\section{Çalışmada Kullanılan Bitki Materyallerinin} Özellikleri

Çalışmada bitki materyali olarak Doğu Akdeniz Geçit Kuşağı Tarımsal Araştırma Enstitüsü ve Dicle Üniversitesi Ziraat Fakültesi tarafından geliştirilen 7 adet pamuk genotipi ile bölge standart çeşitlerinden Stoneville 468 çeşidi kontrol olarak kullanılmıştır. Gossypium hirsutum L. türüne ait olan Stoneville 468 çeşidi, 2006 yılında May-Çukonar San. A.Ş. tarafından tescil ettirilmiştir.

\section{Yöntem}

Sulama Konuları, Toprak Nemi, Sulama Suyu ve Bitki Su Tüketiminin Belirlenmesi

Ekim 20 Mayıs tarihinde mibzer ile yapılmıştır. Ekimden 1 hafta önce toprakta oluşan kesekleri ufaltarak tarlayı düzeltmek, toprağı karıştırarak havalandırmak ve tohum yatağı hazırlamak amacıyla kombikürüm aracıyla sürülen arazi daha sonra tapan ile düzeltilmiştir. Araziye ekimden önce dekara $35 \mathrm{~kg}$ olacak şekilde 20-20-0 (\%20 N, \%20 $\left.\mathrm{P}_{2} \mathrm{O}_{5}\right)$ taban gübresi uygulanmıştır. \%33'lük amonyum nitrat gübresi çiçeklenme başlangıcında ve çiçeklenme başlangıcından yaklaşık 2 hafta sonra 3 'er $\mathrm{kg} \mathrm{da}^{-1}$ olmak üzere toplamda $6 \mathrm{~kg} \mathrm{da}^{-1}$ olarak fertigasyon şeklinde uygulanmıştır.

Denemede ana konuları sulama seviyeleri, alt konuları bitki genotipleri oluşturmuştur. Farklı su seviyeleri; topraktaki nem takip edilerek elverişli nemin \%30 u tüketildiğinde, eksilen nemi tekrardan tarla kapasitesine getirecek kadar sulama suyu uygulaması tam sulama konusu $\left(\mathbf{S}_{100}\right)$ olarak belirlenmiştir. $\mathbf{S}_{100}$ konusunun \% 50 eksiği kadar verilen sulama suyu uygulaması ise $\mathrm{S}_{50}$ konusunu oluşturmuştur. Bölünmüş parseller deneme desenine göre 2 sulama konusu, 8 pamuk genotipi (7 hat, 1 çeşit), ve 3 tekerrürden oluşmaktadır. Çalışmada parsel genişliği $2.80 \mathrm{~m}$, parsel boyu $12 \mathrm{~m}$, iki parsel arası mesafe ise 2 $\mathrm{m}$ olarak belirlenmiştir. Kenar tesir etmenleri düşünülerek çalışma alanının her parselin başından ve sonundan $3 \mathrm{~m}$ boşluk bırakılmıştır. Pamuk tohumları sıra arası 70, sıra üzeri $20 \mathrm{~cm}$ olacak şekilde ekilmiştir. Deneme parsellerinin sulanmasında damla sulama yöntemi kullanılmıştır. Damlatıcı debisi $4 \mathrm{~L} \mathrm{~h}$. 1, kendinden basınçlı 16 mm'lik içten geçik (in-line) borular her siraya bir lateral olacak şekilde döşenmiştir.

Çalışma alanındaki toprak nem içeriğinin takibinde gravimetrik yöntem kullanılmıştır. 5 gün aralıklarla 0-30, 30-60, 60-90 cm derinliklerden alınan toprakların yaş ağırlıkları tartılmış, etüvde $105^{\circ} \mathrm{C}$ de sabit ağırlığa gelinceye kadar kurutulmuştur. Toprağın nemi ağırlık yüzdesi cinsinden belirlenmiştir. Her sulamada parsellere verilen sulama suyu miktarı belirlenirken toprağın kullanılabilir su tutma kapasitesin derinlik cinsinden belirlenmiştir (Güngör ve ark., 2012). Her bir sulama konusuna ait bitki su tüketiminin hesabında su bütçesi eşitliği yöntemi (Eşitlik 1) kullanılmıştır (Howell, 1986; James, 1988).

$\mathrm{ET}=\mathrm{I}+\mathrm{P}-\mathrm{Rf}-\mathrm{Cr}-\mathrm{Dp} \pm \Delta \mathrm{S}$

Eşitlikte;

ET: Bitki su tüketimi (mm), I : Sulama suyu $(\mathrm{mm})$, P: Yağış (mm), Rf: Yüzey akış kayıpları (mm), Dp: Derine 
sızma miktarı (mm), Cr: Kılcal yükseliş (mm), $\Delta \mathrm{S}$ : Kök bölgesinde toprak su içeriğindeki değişimdir $(\mathrm{mm})$.

\section{Kuraklık Tolerans İndekslerinin Belirlenmesi}

Çalışmada 11 adet kuraklık tolerans indeksi yer almaktadır. Söz konusu indeksler için su stresinin olmadığı ve su stresi olan koşulların verim değerleri kullanılmıştır. Su stresinin olmadığı koşullar tam sulamanın yapıldığı S100 konusunun verim değerlerinden alınırken su stresi olan koşullar $\mathbf{S}_{100}$ 'de verilen suyun \%50 eksiği kadar sulama suyunun verildiği $\mathrm{S}_{50}$ konusunun verim değerlerinden elde edilmiştir. Kuraklık tolerans indekslerine ait eşitlikler Çizelge 3'te verilmiştir. Çizelge 3’te yer alan Yp $\mathrm{S}_{100}$ (stressiz konu) konusundan elde edilen verim değerini ifade ederken Ys $\mathrm{S}_{50}$ (stresli konu) konusundan elde edilen verim değerini göstermektedir.

Çizelge 3. Kuraklık tolerans indekslerine ait eşitlikler

\begin{tabular}{lll}
\hline İndeks adı & Formül & Referans \\
\hline Toleranslılı İndeksi (TOL) & Ys-Yp & Rosielle ve Hamblin (1981) \\
Ortalama Verimlilik (MP) & $(Y p+Y s) / 2$ & Rosielle ve Hamblin (1981) \\
Verim Kararlılık İndeksi (YSI) & $Y s / Y p$ & Bouslema veSchapaugh (1984) \\
Harmonik Ortalama (HM) & $2(Y p x Y s) / Y p+Y s$ & Kristin ve ark. (1997) \\
Verim Azalma Oranı (Yr) & $1-(Y s / Y p)$ & Golestani-Araghi ve Assad (1998) \\
Geometrik Ortalama Verimliliği (GMP) & $\sqrt{(Y s x Y p)}$ & Kristin ve ark. (1997) \\
Verim İndeksi (YI) & $Y s / \overline{Y s}$ & Gavuzzi ve ark. (1997) \\
Stres Toleranslılı indeksi (STI) & $(Y p x Y s) / \overline{(Y p)^{2}}$ & Fernandez (1992) \\
Stres Duyarlılı İndeksi (SSI) & $(1-Y s / Y p) /(1-(\overline{Y s} / \overline{Y p}))$ & Fisher ve Maurer (1978) \\
Potansiyel Verim Değerlerinden Elde & $(Y p)^{2} /(\overline{Y p})^{2}$ & Farshadfar ve Sutka (2002) \\
Edilerek Hesaplanan İndeks ( K KTI) & & \\
Stres Koşullarında Elde Edilen Verim & $(Y s)^{2} /(\overline{Y s})^{2}$ & Farshadfar ve Sutka (2002) \\
Değerleriyle Hesaplanan İndeks (K2STI) & &
\end{tabular}

\section{Verilerin Değerlendirilmesi}

Elde edilen verilerin ortalama değerleri PROC ANOVA kullanarak SAS (SAS Institute Inc., Cary, NC, USA) yazılımında yapılmıştır. Ortalamaların karşılaştırılmasında \%5 lik önem düzeyi ile LSD testinden yararlanılmıştır. Tolerans indeksleri arasındaki korelasyon SAS PROC CORR. ile belirlenmiştir. Temel bileşenler (PCA) ve kümeleme (cluster) analizleri SYSTAT version 10 ile yapılmıştır.

\section{BULGULAR ve TARTIŞMA}

Bitki Su Tüketim Değerleri ve Sulama Suyunun Uygulanması

Uygulanan sulama suyu miktarları Çizelge 4 ve bitki su tüketimi değerleri Çizelge 5'te verilmiştir. Bitkilere konulu sulamalara geçmeden önce 1 sulama ve 10 konulu olmak üzere toplam $11 \mathrm{kez}$ sulama yapılmıştır. Sulama mevsimi boyunca tam sulanan $\mathrm{S}_{100}$ konusuna $921.03 \mathrm{~mm}, \% 50$ kisintı yapilan $\mathrm{S}_{50}$ konusuna ise $500.19 \mathrm{~mm}$ sulama suyu uygulanmıştır. Verilecek sulama suyunun hesaplanması açısından bitkilerin su tüketimlerinin dikkate alınması zorunludur. Çizelge 5 yetişme sezonu boyunca sulama suyunda yapılan kısıntının bitki su tüketimi değerlerinin değişmesine sebep olduğunu göstermektedir. Bitki su tüketim değeri $\mathrm{S}_{100}$ konusunda yaklaşı $921 \mathrm{~mm}, \quad \mathrm{~S}_{50}$ konusunda ise $500 \mathrm{~mm}$ çıkmıştır. Bu bilgiler, su stresli konudaki $\left(\mathrm{S}_{50}\right)$ verim $\left(\mathrm{Y}_{\mathrm{S}}\right)$ değerleri ve stressiz konudaki $\left(\mathrm{S}_{100}\right)$ verim $(\mathrm{Yp})$ değerlerinden elde edilecek sonuçlar açısından önemlidir.
Kuraklık Tolerans İndekslerine Bağlı Genotiplerin Karşılaştırması

Genotipler ve kuraklı tolerans indekslerine ait ortalama değerler Çizelge 6'da verilmiştir. Verimi etkileyen çevre faktörlerinden en önemlisi kuraklıktır. Kuraklık tolerans indekslerinin belirlenmesinde stresli ve stressiz koşullar altındaki verimler birlikte değerlendirilir. En uygun indeksin stresli ve stressiz koşular altında önemli korelasyona sahip olması beklenir (Mitra, 2001). Çizelge 6'da genotip ve farklı tolerans indekslerinin ortalama değerleri verilmiştir. Aday 6 stresli ve stressiz koşullarda yüksek verime sahip genotip olarak bulunmuştur. MP değeri fazla olan Aday 6 bu indekse göre yüksek verimde ve su stresine toleranslı genotip olarak seçilebilir. Benzer şekilde Eivazy ve ark. (2013) hem sulanan hem de stres koşullarında yüksek tane verimi olan genotipleri seçmek için MP'yi en iyi kriter olarak bulmuştur. Aday 4'ün diğer genotiplerle karşılaştırıldığında en yüksek HM, MP, GMP, STI ve $\mathrm{K}_{1}$ STI değerlerine sahip olduğu görülmüştür. Dolayısıyla HM, MP, GMP, STI ve $\mathrm{K}_{1}$ STI değerlerinin yüksek çıktığı bu genotip su stresi için dayanıklı olabilir. Singh ve ark. (2015) MP ve GMP'nin yüksek çıktığı pamuk genotiplerinin kuraklık için toleranslı genotip olabileceğini bildirmiştir. Farshadfar ve ark. (2013) K K $_{1}$ STI'nın kuraklık toleransını belirlemek için en uygun gösterge olarak kullanılabileceğini bildirmiştir. Aday 2 diğer tüm genotipler ile kıyaslandığında en yüksek YSI değerine sahip olmuştur. Ve diğer genotiplere karşı hemen hemen tüm indekslerde düşük değere sahip olmuştur. 
Çizelge 4. Toplam sulama suyu miktarları

\begin{tabular}{|c|c|c|c|c|c|c|c|c|c|c|c|c|}
\hline \multirow{2}{*}{$\mathrm{S}$} & \multirow{2}{*}{ KÖS } & \multicolumn{10}{|c|}{ Sulama sayısı } & \multirow{2}{*}{ TSSM (mm) } \\
\hline & & 1 & 2 & 3 & 4 & 5 & 6 & 7 & 8 & 9 & 10 & \\
\hline $\mathrm{S}_{100}$ & 79.3 & 73.34 & 116.78 & 90.94 & 79.73 & 78.16 & 81.37 & 101.03 & 96.41 & 77.57 & 46.4 & 921.03 \\
\hline $\mathrm{S}_{50}$ & 79.3 & 36.67 & 58.39 & 45.47 & 40.37 & 38.58 & 40.69 & 58.01 & 48.21 & 38.79 & 15.7 & 500.19 \\
\hline
\end{tabular}

S: Sulama konuları; KÖS: Konulu sulamalardan önce uygulanan sulama suyu miktarı; TSSM: Toplam sulama suyu miktarı $(\mathrm{mm})$

Çizelge 5. Konulara ait bitki su tüketimi

\begin{tabular}{llllllll}
\hline Konular & $\begin{array}{l}\text { Toplam sulama } \\
\text { miktarı }(\mathrm{mm})\end{array}$ & $\begin{array}{l}\text { Toplam } \\
(\mathrm{mm})\end{array}$ & yaģ̧̆ & $\begin{array}{l}\text { Ekimdeki nem } \\
(\mathrm{mm})\end{array}$ & $\begin{array}{l}\text { Hasat } \\
(\mathrm{mm})\end{array}$ & $\begin{array}{l}\Delta \mathrm{S} \\
(\mathrm{mm})\end{array}$ & $\begin{array}{l}\text { ET } \\
(\mathrm{mm})\end{array}$ \\
\hline $\mathrm{S}_{100}$ & 921.03 & 73.2 & 247.79 & 197.02 & 50.77 & 1045.00 \\
$\mathrm{~S}_{50}$ & 500.17 & 73.2 & 247.79 & 146.82 & 100.97 & 674.34 \\
\hline
\end{tabular}

Aday 2 aynı zamanda Yr, TOL ve SSI ile negatif bir ilişkiye sahiptir. Gholipouri ve ark. (2009) stres koşullarında buğday tane veriminin TOL ve SSI ile negatif bir ilişkide olduğunu ve düşük verimle kuraklığa toleranslı buğday genotiplerini belirlemek için uygun indeks olduğunu belirtmiştir.

SSİ her bir genotip için ortalama değişime göre stresli ve stressiz koşullar arasında verimdeki değişim oranını hesaplar. SSİ değerinin 1'den küçük olması kuraklılığa toleransı, 1'den büyük olması ise kuraklığa hassasiyeti ifade eder (Singh ve ark., 2015; Baloch ve ark., 2011). Aday 2, Aday 3 ve Aday 5 1'den küçük SSI değerlerine sahiptir. Diğer koşullarla birlikte değerlendirildiğinde (TOL ün ve stresli koşullardaki verimin düşük olması) Aday 2, Aday 3, Aday 5'in stresli koşullarda kuraklığa toleranslı genotip oldukları düşünülebilir.

\section{Korelasyon Analizi}

Çizelge 7'de stresli ve stressiz koşullarda hesaplanan kuraklık tolerans indekslerinin korelasyonları verilmiştir. İndeksler arasında en uygun olanı belirlemek amaciyla $\mathrm{Yp}, \mathrm{Ys}_{\mathrm{s}}$ ve diğer tolerans indeksleri arasında korelasyon yapılmıştır (Çizelge 8). Stres ve stressiz koşullardaki bitki verimi ile yüksek korelasyoma sahip indeksler her iki koşulda da yüksek verimle genotipleri ayırt edebildikleri için en iyi olanlardır (Singh ve ark., 2015). Çizelge 8'deki korelasyon matrisinden stresli ve stressiz koşullardaki verimlerle HM, GMP arasında önemli pozitif korelasyon bulunmuştur. Dolayısıyla HM ve GMP iki koşulda da toleranslılığı belirlemek için kullanılabilir. Benzer sonuçlar Sabaghina ve Janmohammadi (2014) ve Toorchi ve ark. (2012) tarafindan da bulunmuştur. Stres koşullarındaki verim ile YI, HM, GMP ve $\mathrm{K}_{2} \mathrm{STI}$ indeksleri arasında pozitif ve önemli korelasyon çıkarken stressiz koşullardaki verim ile HM, Yr, MP, GMP, TOL, SSI ve $\mathrm{K}_{1} \mathrm{STI}$ arasında önemli pozitif korelasyon çıkmıştır. Benzer sonuçlar Gholinezhad ve ark. (2014) tarafından elde edilmiştir. Çizelge 8'de stresli koşuldaki verim ile YSI arasında önemli negatif bir ilişki görülmektedir. Önemli ilişkilere sahip indeksler kuraklık toleransını tanımlayabilirler.

TOL ve SSI değerleri Yp ile önemli pozitif korelasyon gösterirken Ys ile önemsiz negatif korelasyon göstermektedir. Daha yüksek TOL ve SSI değeri her iki koşulda da daha yüksek verim değeriyle, daha düşük TOL ve SSI ise stressiz koşullarda daha fazla verim üretimi ile ilgilidir (Singh ve ark., 2015; Karimizadeh ve ark., 2011).

\section{Temel Bileşenler Analizi (PCA)}

Şekil 1'de genotip ve indekslere ait temel bileşenler analizi, Çizelge 8'de temel bileşenler analizine ait PC1 (1. Faktör), PC2 (2.faktör) değerleri verilmiştir. Temel bileşenler analizi genotip ve indeksler arasındaki ilişkiyi belirlemek için yapılmıştır. Bir çok araştırıcı temel bileşenler analizi ile farklı kriterler için farklı genotipleri karşılaştırmışlardır (Golabadi ve ark., 2006; Gholinezhad ve ark., 2014; Singh ve ark., 2015). Analiz sonuçlarına göre toplam varyansın \%67.53’ü birinci faktör, \%29'u ise ikinci faktör olmuştur. Toplam verim varyasyonun \%67.53'ü olan birinci bileşende YSI'nın dışındaki tüm indekslerde pozitif korelasyon görülmüştür. Bu yüzden bu bileşen verim ve kuraklık toleransı ile ilgilidir (Akçura ve ark., 2011). Yüksek PC1 değerine sahip genotiplerin her iki koşulda da yüksek verim değerine sahip olması beklenir.

Benzer sonuçlar Golabadi ve ark. (2006), Singh ve ark. (2015) tarafından bulunmuştur. Toplam verim varyasyonunun \%29'una sahip olan ikinci bileşen YSI ile pozitif korelasyon göstermiştir. PC2 stres ortamında verim ve strese duyarlılıkla ilgilidir. $\mathrm{Bu}$ yüzden PC1 potansiyel verimi, PC2 strese duyarlılığ ifade etmiştir (Singh ve ark., 2015; Gholinezhad ve ark., 2014). PC1 ve PC2 incelendiğinde Aday 2 yüksek PC1 fakat en düşük PC2 değerine sahip olmuştur. Bu durum Aday 2'nin kuraklığa dayanıklı olduğunu göstermektedir. HM, GMP, MP, STI, K $\mathrm{K}_{1} \mathrm{STI}$ arasında yakın ilişkiler bulunmaktadır. PC1 de yer alan kısım kuraklığa toleranslılığ ifade etmektedir. Benzer sonuçlar Gholinezhad ve ark. (2014) tarafindan bulunmuştur. 
Çizelge 6. Genotipler ve tolerans indekslerinin ortalama değerleri

\begin{tabular}{|c|c|c|c|c|c|c|c|c|c|c|c|c|c|}
\hline Genotip & Yp $\left(\mathrm{kgda}^{-1)}\right.$ & $\mathrm{Ys}_{\mathrm{S}}\left(\mathrm{kgda}^{-1}\right)$ & YI & HM & $\mathrm{Yr}$ & MP & YSI & GMP & TOL & SSI & STI & $\mathrm{K}_{1} \mathrm{STI}$ & $\mathrm{K}_{2} \mathrm{STI}$ \\
\hline Aday 1 & $441.36^{\mathrm{ab}}$ & 354.88 & 1.00 & $393.36^{\mathrm{ab}}$ & $0.19^{a}$ & $398.12^{\mathrm{ab}}$ & $0.81^{\mathrm{b}}$ & $395.73^{\mathrm{ab}}$ & $86.48^{a}$ & $1.36^{\mathrm{a}}$ & $0.92^{\mathrm{ab}}$ & $1.12^{\mathrm{b}}$ & $1.01^{\mathrm{a}}$ \\
\hline Aday 2 & $277.98^{c}$ & 340.31 & 0.96 & $305.69^{c}$ & $-0.22^{\mathrm{b}}$ & $309.14^{\mathrm{c}}$ & $1.22^{\mathrm{a}}$ & $307.41^{c}$ & $-62.33^{b}$ & $-1.56^{b}$ & $0.55^{\mathrm{c}}$ & $0.45^{c}$ & $0.92^{\mathrm{a}}$ \\
\hline Aday 3 & $413.26^{\mathrm{ab}}$ & 360.00 & 1.01 & $384.49^{b}$ & $0.12^{\mathrm{a}}$ & $386.63^{\mathrm{ab}}$ & $0.81^{b}$ & $385.56^{\mathrm{b}}$ & $53.26^{\mathrm{a}}$ & $0.88^{a}$ & $0.86^{b}$ & $0.95^{b}$ & $1.03^{\mathrm{a}}$ \\
\hline Aday 4 & $458.62^{\mathrm{ab}}$ & 381.12 & 1.07 & $415.47^{\mathrm{a}}$ & $0.16^{\mathrm{a}}$ & $419.17^{\mathrm{a}}$ & $0.84^{\mathrm{b}}$ & $417.66^{\mathrm{a}}$ & $77.50^{\mathrm{a}}$ & $1.15^{\mathrm{a}}$ & $1.02^{\mathrm{a}}$ & $1.65^{\mathrm{a}}$ & $1.16^{\mathrm{a}}$ \\
\hline Aday 5 & $385.95^{\mathrm{b}}$ & 349.62 & 0.98 & $366.67^{b}$ & $0.09^{a}$ & $367.79^{\mathrm{b}}$ & $0.91^{b}$ & $367.23^{\mathrm{b}}$ & $36.34^{\mathrm{a}}$ & $0.64^{\mathrm{a}}$ & $0.79^{b}$ & $0.84^{\mathrm{bc}}$ & $0.97^{\mathrm{a}}$ \\
\hline Aday 6 & $466.19^{a}$ & 346.16 & 0.97 & $390.91^{\mathrm{ab}}$ & $0.22^{\mathrm{a}}$ & $406.18^{a}$ & $0.78^{b}$ & $398.96^{\mathrm{ab}}$ & $120.03^{\mathrm{a}}$ & $1.54^{\mathrm{a}}$ & $0.93^{\mathrm{ab}}$ & $1.16^{b}$ & $0.96^{\mathrm{a}}$ \\
\hline Aday 7 & $434.57^{\mathrm{ab}}$ & 347.74 & 0.98 & $385.69^{b}$ & $0.20^{\mathrm{a}}$ & $391.15^{\mathrm{ab}}$ & $0.80^{b}$ & $388.41^{\mathrm{ab}}$ & $86.83^{\mathrm{a}}$ & $1.37^{\mathrm{a}}$ & $0.88^{\mathrm{ab}}$ & $1.19^{b}$ & $0.97^{a}$ \\
\hline Stonville 468 & $441.19^{a b}$ & 357.84 & 1.01 & $395.02^{\mathrm{ab}}$ & $0.19^{a}$ & $399.81^{\mathrm{ab}}$ & $0.82^{\mathrm{b}}$ & $397.26^{\mathrm{ab}}$ & $83.36^{\mathrm{a}}$ & $1.29^{\mathrm{a}}$ & $0.92^{\mathrm{ab}}$ & $1.11^{\mathrm{b}}$ & $1.02^{\mathrm{a}}$ \\
\hline
\end{tabular}

Çizelge 7. Stresli ve stressiz koşullarda kuraklık tolerans indekslerinin korelasyon katsayıları

\begin{tabular}{|c|c|c|c|c|c|c|c|c|c|c|c|c|}
\hline & $\mathrm{Yp}$ & Ys & $\mathrm{YI}$ & $\mathrm{HM}$ & $\mathrm{Yr}$ & $\mathrm{MP}$ & YSI & GMP & TOL & SSI & K1STI & K2STI \\
\hline $\mathrm{Yp}$ & 1.000 & & & & & & & & & & & \\
\hline Ys & $0.069^{n s}$ & 1.000 & & & & & & & & & & \\
\hline YI & $0.072^{\mathrm{ns}}$ & $0.999 * *$ & 1.000 & & & & & & & & & \\
\hline HM & $0.875^{* *}$ & $0.520^{* *}$ & $0.522^{* *}$ & 1.000 & & & & & & & & \\
\hline $\mathrm{Yr}$ & $0.942^{* *}$ & $-0.151^{\mathrm{ns}}$ & -0.148 & $0.761^{* *}$ & 1.000 & & & & & & & \\
\hline MP & $0.951 * *$ & $0.373^{\mathrm{ns}}$ & $0.375^{* *}$ & $0.974 * *$ & $0.829 * *$ & 1.000 & & & & & & \\
\hline YSI & $-0.942^{* *}$ & $0.151^{\mathrm{ns}}$ & $0.148^{\mathrm{ns}}$ & $-0.761^{* *}$ & $-1.000 * *$ & $-0.829 * *$ & 1.000 & & & & & \\
\hline TOL & $0.947 * *$ & $-0.254^{\mathrm{ns}}$ & $-0.251^{\mathrm{ns}}$ & $0.680 * *$ & $0.962^{* *}$ & $0.802^{* *}$ & $-0.962^{* *}$ & $0.746^{* *}$ & 1.000 & & & \\
\hline SSI & $0.941 * *$ & $-0.155^{\mathrm{ns}}$ & $-0.153^{\mathrm{ns}}$ & $0.758^{\mathrm{ns}}$ & $0.999 * *$ & $0.827 * *$ & $-0.999 * *$ & $0.798 * *$ & $0.962^{* *}$ & 1.000 & & \\
\hline K1STI & $0.730 * *$ & $0.363^{\mathrm{ns}}$ & $0.374^{\mathrm{ns}}$ & $0.776^{* *}$ & $0.61 * *$ & $0.791 * *$ & $-0.610^{\mathrm{ns}}$ & $0.788 * *$ & $0.591 * *$ & $0.613^{* *}$ & 1.000 & \\
\hline K2STI & $0.082^{\mathrm{ns}}$ & $0.998 * *$ & $0.998 * *$ & $0.529 * *$ & $-0.139^{\mathrm{ns}}$ & $0.385^{\mathrm{ns}}$ & $0.139^{\mathrm{ns}}$ & $0.459 *$ & $-0.241^{\mathrm{ns}}$ & $-0.143^{\mathrm{ns}}$ & $0.395^{\mathrm{ns}}$ & 1.000 \\
\hline
\end{tabular}

ns: önemsiz, ${ }^{*},{ }^{* *}$ sirasiyla $\mathrm{p}<0.05$ ve $\mathrm{p}<0.01$ düzeyinde önemlidir. 
Çizelge 8. Genotip ve indeksler için temel bileşen analiz sonuçları

\begin{tabular}{lrl}
\hline Kuraklık tolerans indeksleri & 1 & \multicolumn{1}{c}{2} \\
\hline Yp & 0.975 & -0.186 \\
Ys & 0.252 & 0.964 \\
YI & 0.261 & 0.963 \\
HM & 0.955 & 0.278 \\
Yr & 0.903 & -0.406 \\
MP & 0.986 & 0.124 \\
YSI & -0.903 & 0.406 \\
GMP & 0.977 & 0.201 \\
TOL & 0.862 & -0.491 \\
SSİ & 0.902 & -0.410 \\
STI & 0.975 & 0.208 \\
K1STI & 0.803 & 0.201 \\
K2STI & 0.272 & 0.961 \\
Toplam (\%) & 67.53 & 29.00 \\
\hline
\end{tabular}

\section{Kümeleme Analizi}

Kuraklık toleransı çalışmalarında Gholinezhad ve ark. (2014); Singh ve ark. (2015); Golabadi ve ark. (2006); Safahani Langroodi ve ark. (2013) gibi bir çok araştırıcı cluster analizi yapmıştır. Şekil 2'de genotiplerin kuraklık indekslerine bağlı kümeleme (cluster) analizi verilmiştir. Şekil 2'de yer alan çoklu değişken kümeleme analizi ward metodu kullanılarak elde edilmiştir (Astel ve ark., 2007). Kümeleme analizine göre incelenen genotipler stresli ve stressiz koşullara bağlı olarak 2 gruba ayrılmıştır. Bu nedenle kuraklık toleransı için genotipler arasında önemli farklılıklar çıkmıştır. Benzer özellik gösteren genotipler aynı grupta yer almıştır. Kümeler sneath indeksine göre maksimum aralığın 2/3'ü olacak şekilde oluşturulmuştur (Astel ve ark., 2007; Tanriverdi ve ark., 2010). Şekil 2'ye göre Grup 1 sadece Aday 2 den oluşmaktadır. Aday 3, Aday 7, Aday 1, Stonville 468, Aday 5, Aday 6, Aday 4 Grup 2 de yer almıştır Analizden de anlaşılacağı üzere Aday 2 diğer genotiplerden oldukça farklı ve tek başına bir grup olmuştur. Grup 2 de ki genotiplerin cluster sinıflandırmasına göre benzer özellikler taşıdığı düşünülebilir. Bu gruplamalardan Aday 2 nin stressiz koşullarda düşük verimli fakat kuraklığa dayanıklı, diğer adayların sulu koşullarda yüksek verimli ancak kuraklığa duyarlı olduğu söylenebilir.

\section{SONUÇ}

Çalışma sonucunda elde edilen bulgular tüm istatistik analizlere göre bir bütün olarak değerlendirildiğinde HM, MP,GMP, STI, K 1 STI indekslerinin stresli ve stressiz koşullarda uygulanabilirliğini Aday 4 genotipinde ortaya koymuştur. MP değeri en fazla Aday 6 genotipinde bulunmuştur. Dolayısıyla Aday 6 bu indekse göre sulu koşullarda yüksek verimli ve su stresine toleranslı genotip olarak seçilmiştir. SSI indeksi Aday 2 genotipinde en düşük değerde çıkmıştır. SSI'nın 1'den düşük oluşu genotipin toleranslı olduğunu göstermiştir. Aynı zamnada SSI ile MP, GMP, Yp, GMP, STI, TOL arasında önemli pozitif korelasyon bulunmuştur. Ortalama karşılaştırma (lsd), temel bileşenler analizi (pca) ve kümeleme (cluster) analizi sonucunda Aday 2 genotipinin kuraklığa yüksek oranda toleranslı olduğu anlaşılmıştır.

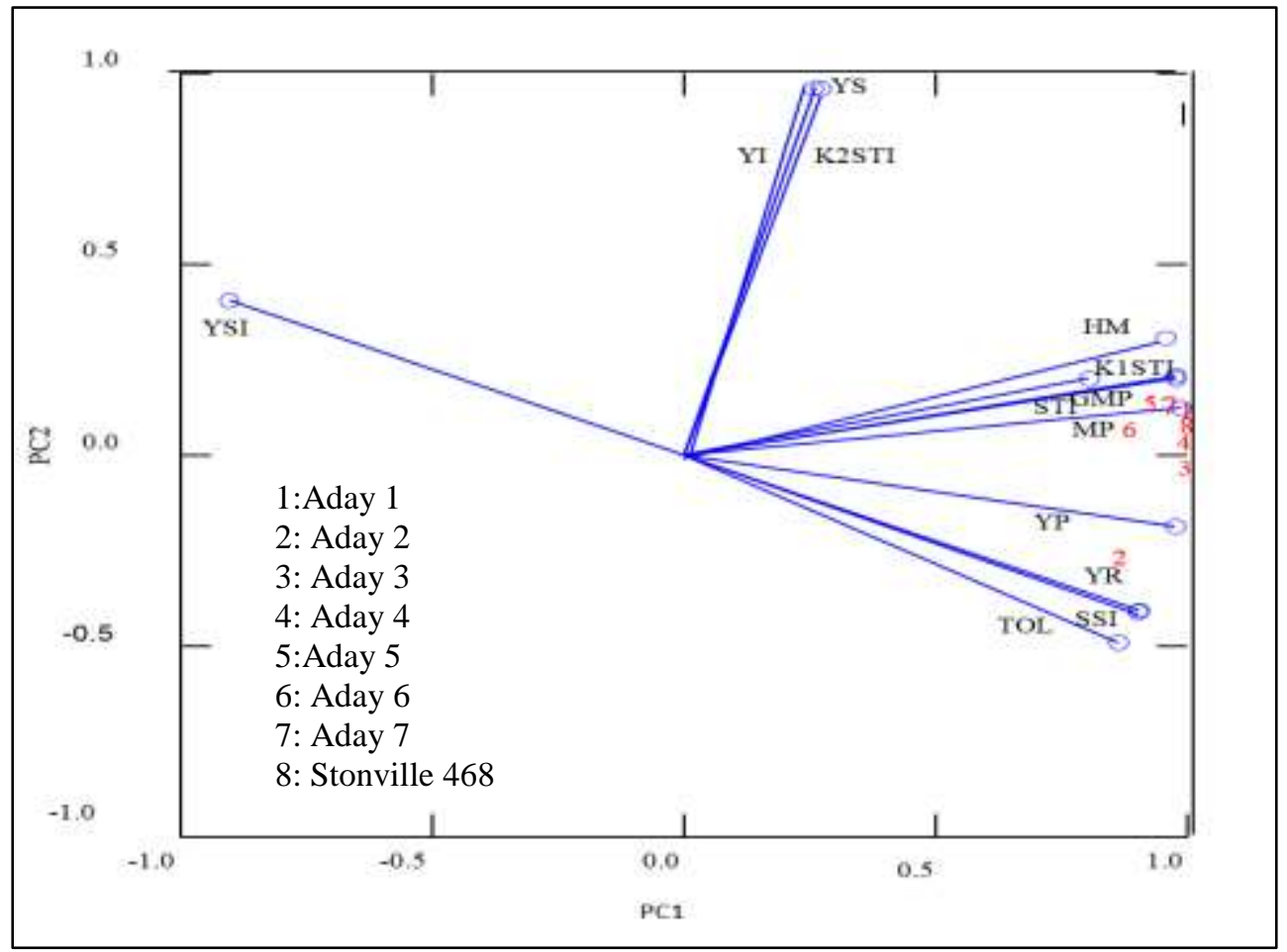

Şekil 1: Temel bileşenler analizi 


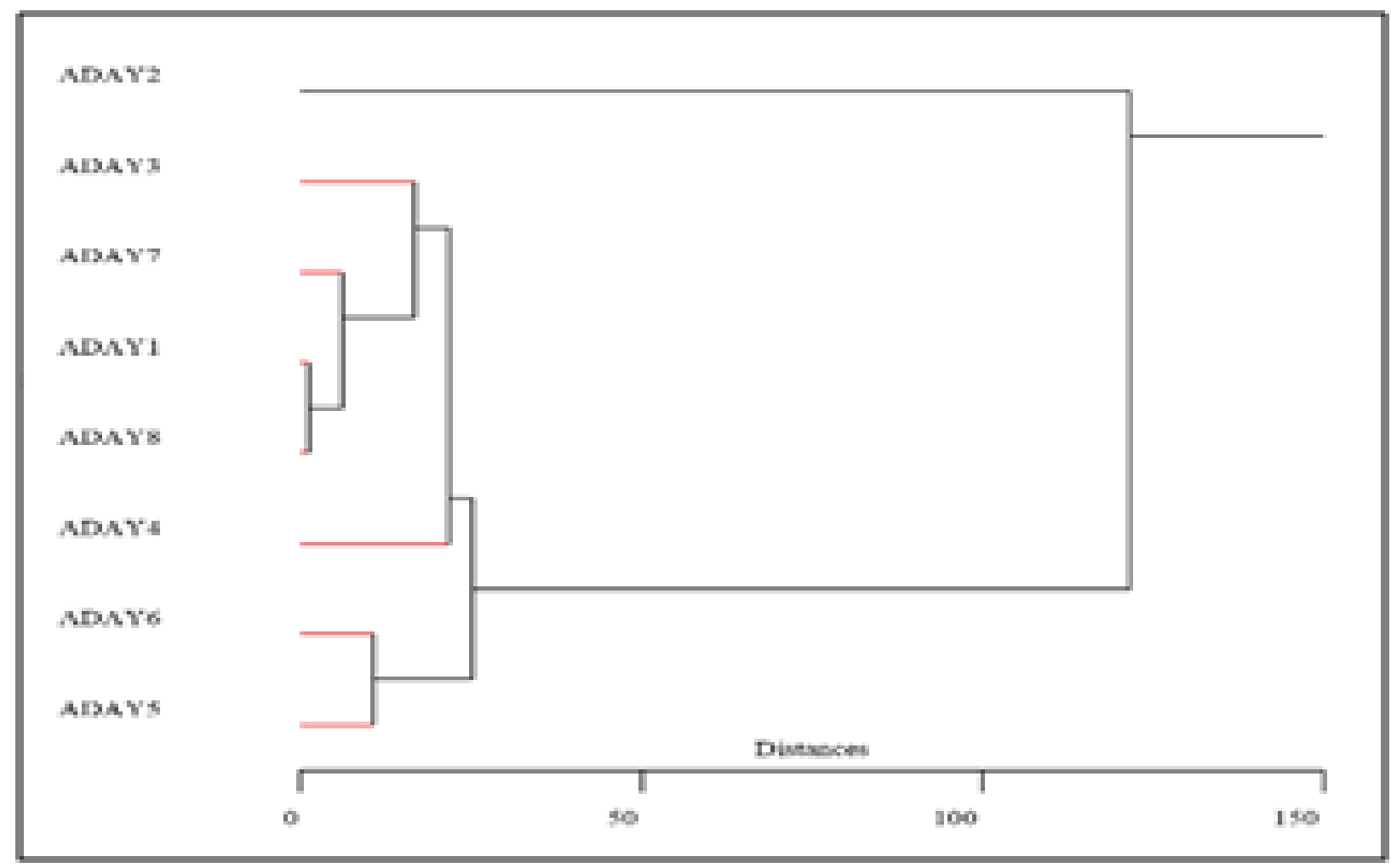

Şekil 2. Genotiplerin kuraklık tolerans indekslerine bağlı kümeleme (cluster) analizi

Kuraklık bazı genotiplerin verimini önemli ölçüde azaltmıştır. Bazı genotipler kuraklığa toleranslı olduğu için daha az etkilenmiştir. Bu nedenle kurak ve yarı kurak bölgelerde pamuk yetiştiriciliği için su stresine dayanıklı genlerden elde edilen tohum kullanılarak daha fazla verim elde edilebilir. Üreticilerin kuraklığa toleranslı genotiplerin yetiştiriciliğinde sulama suyunda kısıntı yaparak suyu daha verimli kullanmaları sağlanabilir. Kısıntılı sulama ve kuraklığa toleranslı genotipler gelecekte azalması beklenen su kaynaklarının oluşturabileceği besin kaynağı yetersizliğinin önüne geçilmesinde şimdiden alınması gereken önlemlerden ikisidir.

\section{KAYNAKLAR}

Anonim 2015. Kahramanmaraş Meteoroloji İl Müdürlüğ̈̈. https://mgm.gov.tr/?il=Kahraman mara \%C5\%9F (Erişim Tarihi : 10.10.2015).

Anwar J, Subhani GM, Makhdoom H, Javed A, Mujahid H, Munir M 2011. Drought tolerance indices and their correlation with yield in exotic wheat genotypes. Pakistan J Bot, 43(3):1527-1530.

Akçura M, Partigoç F, Kaya Y 2011. Evaluating of drought stress tolerance based on selection indices in Turkish bread wheat landraces. The Journal of Animal \&Plant Sciences, 21(4): 700-709.

Astel A, Tsakovski S, Barbieri P, Simeonov V 2007. Comparison of self-organizing maps classi- fication approach with cluster and principal com- ponents analysis for large environmental data sets. Water Research, 41: 4566-4578. doi:10.1016/j.watres.

Baloch MJ, Khan NU, J WA, Hassan G, Khakgwani
AA, Soomro ZA, Veesar NF 2011. Drought tolerance studies through wssi and stomata in upland cotton. Pak.J.Bot., 43(5):2479-2484.

Blum A 1988. Plant breeding for stress environments. CRC Press, Florida. P.212.

Bouslama M, Schapaugh WT 1984. Stress tolerance in soy- bean. Part 1: evaluation of three screening techniques for heat and drought tolerance. Crop Sci., 24: 933-937.

Drikvand R, Doosty B, Hosseinpour T 2012. Response of rainfed wheat genotypes to drought stress using drought tolerance indices. J Agr Sci, 4(7):126-131.

Eivazi AR, Mohammadi S, Rezaei M, Ashori S, Hossien Pour F 2013. Effective selection criteria for assessing drought tolerance indices in barley (Hordeum vulgare L.) accessions. International Journal of Agronomy and Plant Production, 4 (4):813-821.

Farshadfar F, Sutka J 2002. Screening drought tolrerance criteria in maize. Acta Agron. Hung., 50(4):411-416.

Farshadfar E, Poursiahbidi MM, Safavi SM 2013. Assessment of drought tolerance in land races of bread wheat based on resistance/tolerance indices. International Journal of Advanced Biological and Biomedical Research, 1(2):143-158.

Fernandez GCJ 1992. Effective selection criteria for assess- ing plant stress tolerance", In: C.G. Kuo, editor, Adaptation of Food Crops to Temperature and Water Stress: Proceedings of an International Symposium, Taiwan. 13- 18 Aug. 1992. Asian Vegetable Res. and Dev. Ctr., Shanhua, Tainan, pp 
257-270.

Fischer AT, Maurer R 1978. Drought resistance in spring wheat cultivars. I. Grain yield responses Aust. J. Agric Res, 29: 897-912.

Ganjali A, Bagheri A, Porsa H 2009. Evaluation of chickpea (Cicer arietinum L.) germplasm for drought resistance. Journal of Agronomic Research of Iran, 7(1):183-194.

Gavuzzi P, Rizza F, Palumbo M, Campaline RG, Ricciardi GL, Borghi B 1997. Evaluation of field and laboratory predictors of drought and heat tolerance in winter cereals. Can. J. Plant Sci., 77:523-531.

Gholinezhad, E., Darvishzadeh, R., Bernousi, I 2014, "Evaluation of Drought Tolerance Indices for Selection of Confectionery Sunflower (Helianthus annus L.) Landraces under Various Environmental Condition", Not Bot Horti Agrobo, 42(1):187-201.

Gholipouri A, Sedghi M, Sharifi RS, NM Nazari 2009. Evaluation of drought tolerance indices and their relationship with grain yield in wheat cultivars. Recent Res.Sci. Technol., 1(4):195-198.

Golabadi M, Arzani A, Mirmohammadi SAM 2006. Assessment of drought tolerance in segregating popula- tions in durum wheat. Afr. J. Agric. Res, 1:162-171

Golestani-Araghi S, Assad MT 1998. Evaluation of four screening techniques for drought resistance and their rela- tionship to yield reduction ratio in wheat. Euphytica, 103: 293-299.

Güngör Y, Erözel AZ, Yıldırım O 2012. Sulama Kitabı. Ankara Üniversitesi. Ziraat Fakültesi. Tarımsal Yapılar ve Sulama Bölümü. Yayın No:1592.s:291.

Howell TA, Musick JT, Tolk JA, 1986. Canopy Temperature of Irrigated Winter Wheat. Transaction of ASAE 29 (6).:1692-1699.

Jabbari H, Akbari GA, Daneshian J, Alahdadi I, Shahbazian N 2008. Utilization ability of drought resistance indices in sunflower (Heliantus annus L.) hybrids. EJCP 1(4):1-17.

James LG 1988. Principles of Farm Irrigation System Design. John Wiley and Sons. Inc. New York. 543s.

Kaçar MM, Ünlü M 2008. Farklı Su ve Gübre Sistemlerinin Pamuk Bitkisinde $\mathrm{Su}$ Stres İndeksinin Değişiminin İncelenmesi. ÇÜ Fen Bilimleri Enstitüsü Dergisi, 19(2):22-34.

Karimizadeh R, Mohammadi M, Ghaffaripour S,
Karimpour F, Shefazadeh MK 2011. Evaluation of physiological screening techniques for droughtresistant breeding of durum wheat genotypes in Iran. Afr. J. Biotechnol., 10:12107-12117.

Khalili M, Naghavi MR, Pour Aboughadareh AR, Talebzadeh SJ 2012. Evaluating of drought stress tolerance based on selection indices in spring canola cultivars (Brassica napus L.). Journal of Agricultural Science, 4(11):78-85.

Kristin AS, Senra RR, Perez FI, Enriquez BC, Gallegos JAA, Vallego PR, Wassimi N, Kelley JD 1997. Improving common bean performance under drought stres. Crop Sci., 37: 43-50.

Maya F 2007. Farklı Su ve Gübre Sistemlerinde Pamuk Bitkisinde Yaprak $\mathrm{Su}$ Potansiyelinin Değişimi. Çukurova Üniversitesi, Fen Bilimleri Enstitüsü, Tarımsal Yapılar ve Sulama Anabilim Dalı, Yüksek Lisans Tezi, Adana, s: 44.

Mitra J 2001. Genetics and geetic improvement of drought resistance in crop plants. Curr. Sci., 80:758-762.

Rosielle AA, Hamblin J 1981. Theoretical aspect of selection for yield in stress and non-stress environment. Crop Sci., 21: 943-946.

Sabaghina N, Janmohammadi M 2014. Evaluation of selection for drought tolerance in some chickpea (Cicer arietinum L.) genotypes. Acta Technologica Agriculturae, p.6-12. DOI: 10.2478/ata-2014-0002.

Safahani Langeroodi AR, Kamkar B, Ataei M, Teixeira Da Silva A 2013. Assessment of the response of sunflower cultivars to water shortage using various stress tolerance indices. Int J Agron Plant Prod., 4(7):1628-1636.

Singh C, Kumar V, Prasad I, Patil VR, Rajkumar BK. 2015. Response of Upland Cotton (G. hirsutum L.) Genotipypes to Drought Stress Using Drought Tolerance Indices. J. Crop Sci. Biotech., 19 (1): 5359.

Tanrıverdi Ç, Alp A, Demirkıran AR, Üçkardeş F 2010. Assessment of surface water quality of the Ceyhan River basin, Turkey. Environ Monit Assess, (2010) 167:175-184.

Toorchi M, Naderi R, Kanbar A, Shakiba MR 2012. Response of spring canola cultivars to sodium chloride stres. In Annals of Biological Research, no. 2 , pp. 312-322. 